\title{
Affording Support in the Response to the Welfare Needs of Children Affected by AIDS
}

\section{Chris Desmond}

\begin{abstract}
1 Introduction
Families, communities, faith-based organisations and NGOs try and support the welfare needs of children affected by HIV and AIDS whether they can afford to or not. Families in particular carry the bulk of the costs associated with current support (Foster 2005). Is this provision adequate? If not, can developing countries' governments afford to support those families caring for children so that the care provided is at least adequate? And what constitutes

'adequate'? This article argues that governments can afford to provide support and specifically examines the affordability of cash transfers.
\end{abstract}

Children are affected by HIV and AIDS in a number of ways. Children are themselves infected, they live with ill caregivers and in households that lose income and support as a result of illness, and many suffer the loss of parents and providers. If they are unable to stay in their homes, most dislocated children including orphans are taken in by other households. This can affect the welfare of children already present in these households as resources are then more thinly spread (Monasch and Boerma 2004). In highly affected regions, arguably almost all children are affected as illness and death increase and children experience the loss of community members, teachers, healthcare providers and others who play a role in their care and communities.

The impacts of infection are magnified by poverty which concentrates impacts in poor communities. Families which respond in these difficult contexts have the fewest resources with which to provide care (Foster 2005) and often struggle and need support. The literature examining household-level impacts of HIV and AIDS provides many examples of the hardship undergone by households during adult illness and eventual death (UNAIDS 1999). The literature further documents how, as a result of the impact or unequal treatment by their new carers, many fostered children suffer and have poorer outcomes than other children (Arnab and SerumagaZake 2006; Beegle et al. 2005; Gregson et al. 2005). The problem is not limited to those directly affected by illness in the household and parental and caregiver loss; children in households that take in dislocated children also suffer materially (Ainsworth et al. 2005; Monasch and Boerma 2004). These impacts must be considered in context, as in some instances the situation of children in general is so poor that it is indistinguishable from the situation faced by orphans (Richter and Foster 2006).

Both practically and morally those caring for children affected by HIV and AIDS need support. They are often unable to provide care even to the same low standard provided to other poor children and they are taking on the cost of what is a national problem. For the poor to do this without support, or to receive support only from other poor people, is difficult to justify.

Providing for access to water, sanitation, and freely accessible health and education services are obvious governmental responsibilities.

The focus here is the provision of support for the care of children. Alternatives to family care are expensive and particularly for young children, damaging to their development and, except as a last resort or as a temporary measure, have no place in a 
large-scale response. Families are the only institution capable of providing direct care to children on the required scale and more importantly, they are generally the best environment for children to develop. Given these factors, the role of government is to support families in providing care to children.

This article examines the affordability of providing such support. An argument can be made that governments cannot afford not to support the care of children, as the adverse long-term impacts of lack of support on their health, education and development will be too great in terms of future economic losses. This argument, however, still frames the problem in cost-benefit analysis terms and suggests a trade-off between economic growth and child wellbeing. The question is reframed as: Can a country afford the costs of providing adequate care to children taking into consideration the impact of these efforts on economic growth? However, the objective of development needs to be clarified - it is broader than just economic growth and includes child welfare itself. A country can hardly claim to be developing if the situation of its children is deteriorating, regardless of its economic growth. Rather, child wellbeing is part of the goal of development and any thought of sacrificing child wellbeing for growth cannot be justified except, possibly, if the benefits of growth achieve broader development at a later stage. Without economic growth, development is difficult, if not impossible, so it is necessary to consider if there is a trade-off between development today and development in the future and, if there is, to ask where the sacrifice should be made. The question from this perspective is then: to what extent can developing countries' governments afford to support families in caring for children affected by HIV and AIDS today without making too great a sacrifice of future development? Even following reformulation, this question is only relevant if we assume that responding to children today will have a negative impact on economic growth and the prospect of providing for children in the future.

This article argues that much can be done, even though there is a ceiling that must be considered to prevent too great a sacrifice of future development. Below the ceiling, responses to children today can actually positively affect economic growth and increase the potential for future development. Furthermore. the height of the ceiling is not fixed and will vary depending on the manner of intervention. The argument will be made that, for countries without the tax base to finance such responses, international aid will be required, but that to begin the response and start to meet basic needs the amounts involved are a small fraction of current pledges and that their use for this purpose will not have negative impacts on the macroeconomic stability of recipient countries. Finally, it will be argued that, while aid is a viable short-term option, it is not an appropriate long-term solution and that the call for a fairer global economic system should be directly linked to debates such as this.

The arguments presented in this article are based on the generic situation in highly affected regions. There will of course be variations in country context that cannot be dealt with here.

\section{The response to children affected by HIV and AIDS}

Any response to HIV and AIDS is at some level a response to the impacts on children. There are many linkages between these impacts and the broader response framework. Prevention aims to keep children and the adults who care for them uninfected. Treatment keeps caregivers and parents alive. Mitigation efforts seek to reduce the economic and social impacts in the societies in which children live. Treatment and prevention have direct implications for children, and there has already been considerable debate on the costs and affordability of these interventions (UNAIDS 2005). This article is interested in the affordability of responses specifically directed at the welfare of children, particularly those directed at strengthening families. There are other interventions which are child-specific, especially education and health services. The returns on investments in these sectors are well established and will not be revisited here.

When considering affordability, it is necessary to be clear on what the costs are. Stover et al. (2006) estimate the costs associated with supporting the needs of orphans and vulnerable children. They recognise the role of the family and the context of poverty and the resultant need for support. They estimate the unit cost of supporting education, nutrition, healthcare, minimal household costs, community support and organisational costs. They then examine the costs of providing these services depending on the coverage envisaged. Their focus is on the number of orphans (maternal or double) and 
those near to being orphaned and what covering these categories would cost. The results suggest a total cost for a global response of US\$1.1-4.4 billion per annum by 2010 , depending on who is covered. The largest cost component is associated with food, followed closely by education. The costing has a number of limitations and it is important to note that the estimation considered only the costs to external service providers responding to orphans. It assumes the increasing use of volunteers which is both unlikely and not costless as implied by the method used. The costs to households are not included. In addition, Stover's exercise assumes that every child that needs support needs support at the same level.

This final limitation indicates a conceptualisation of the problem which sees the child only and not the family. The child is seen outside any social context with no existing support and the cost to the service provider is assumed to be the cost of providing all forms of support from scratch. In reality, children are typically receiving some support within families. The problem is that, given resource constraints, this support is insufficient. Seeing the child as part of a family and already receiving some level of support implies considering that level rather than assuming it entirely absent.

The costing provides a sense of the scale of resources required and raises the difficult issue of targeting in the context of widespread poverty. As a result of the epidemic, children face a range of impacts which stretch across a continuum from those which are specific to HIV and AIDS (e.g. HIV infection in a child), to those which while they are caused by the epidemic are not specific only to it, such as impacts associated with increased poverty, and those inbetween. The last category of semi-specific impacts includes living with an ill caregiver or experiencing disproportionate impacts of household poverty as a result of being orphaned and discriminated against or separated from parents because of migration. Impacts at the specific end of the continuum require specialised targeted responses (e.g. treatment), those in-between require general responses that are HIV and AIDS sensitive, and the non-specific impacts, such as those related to household poverty, should be addressed as part of general responses such as general poverty reduction measures.

In examining the affordability of welfare interventions and focusing on efforts to strengthen family capacity, semi-specific and non-specific impacts have central importance. These typically relate to the interaction between poverty and the epidemic where strong families have the potential to shield children from impact.

The negative implications of poverty for children are well established and are not specific to children impoverished as a result of HIV and AIDS. The psychological impact of dealing with adult illness and losing caregivers and parents, the discrimination against children whose parents have died, and the stigma of family illness are not entirely HIV-specific problems, but children affected by AIDS are more likely to experience these problems (Cluver and Gardner 2006). In the case of both the non-specific and semi-specific impacts, responding only to those experiencing these impacts as a result of the epidemic is difficult to justify. It is important to know that children are more at risk as a result of the epidemic and to consider this in the design of interventions and the selection of areas to target responses, but to consider only the cause of a problem at the delivery stage of an intervention is inappropriate, as the seriousness of the problem should surely be the primary concern. The appropriate response in terms of strengthening families is to target those families whose children's welfare is most at risk, regardless of cause, but in a way that is sensitive to the more specific impacts of HIV and AIDS.

Poverty plays a major role in the realisation of risks for children associated with HIV. Families are better able to support children affected by AIDS if they are not poor. For this reason, the economic strengthening of affected families should be a central aspect of the welfare response. This article focuses on the affordability of cash transfers to poor households as a means of mitigating the impacts of poverty on children, while at the same time being sensitive to and including those affected by the epidemic. Cash transfers are discussed as they are a possible core aspect of a response in their own right, while facilitating access to other services and means of support. Other programmes and supportive services are also required, particularly those to deal with specific impacts such as child infections. However, the bulk of the costs identified by Stover et al. (2006) relate to material goods and healthcare. The provision of healthcare and education are important but are dealt with elsewhere. This article argues that a more efficient approach to providing material support is 
through cash transfers to household and, as noted by Stover et al. (2006), such material resources comprise the major costs of intervention.

A number of middle-income countries have shown that cash transfer interventions are affordable. Mexico, Brazil, South Africa and Namibia, among many others, have some type of scheme. Cash transfers are more difficult in low-income countries. While countries such as Lesotho have shown that cash transfers, in that case pensions, can be financed from their own budgets, at least at a low level, in the short term any meaningful expansion of family support of this type needs international aid.

The International Labour Organization (ILO) conducted a modelling exercise that examined the costs of a cash transfer and a broader social protection package in low-income African countries. The package included a universal old age pension, universal primary education, primary healthcare and a child benefit. The exercise estimated that a child benefit of US $\$ 0.25 /$ day for each child up to the age of 14 years would cost 1.5-4.5 per cent of GDP, depending on the setting. The package as a whole was costly, and includes more general components than are being discussed here, with the major cost driver being the provision of healthcare (48-60 per cent of total). Including healthcare, the total cost in most countries examined was estimated to be 5-15 per cent of GDP (Pal et al. 2005).

The amounts involved in providing small cash transfers are low relative to total foreign aid. For example, it has been estimated that if a recent Zambian pilot, involving US\$15 per month per household to the poorest 10 per cent of households, were implemented in all low-income countries in Africa, it would cost only 3 per cent of the aid to Africa agreed at Gleneagles (ILO modelling reported in DFID 2005a). Extrapolating from one country to a continent and comparing it with committed but not delivered funds and doing so without noting that the 3 per cent does not consider the possible doubling of costs associated with technical assistance which typically accompanies international aid, is problematic, but still highlights the small amounts involved relative to international aid debates.

The Zambian pilot, the existing programmes in middle-income countries, or the ILO example above may not be the appropriate designs to follow. Much more discussion is needed to determine how much is enough. But these cases highlight the feasibility of such programmes in middle- and low-income countries and it is this type of programme which is argued to be appropriate. In middle-income countries they could be financed through tax, while in low-income countries there would likely be need for donor support. The question in both settings is at what point the additional government expenditure will result in the negative consequence of reduced economic growth to the point that the benefits to development gained as a result of the expenditure are outweighed by the costs to future development associated with the impact on economic growth.

There are established links between child survival, school enrolment and future economic growth, although evidence of the links between government expenditure and child outcomes in terms of health and education is mixed (Anderson and Hague 2007). Cash transfers are a particular type of government expenditure and there is strong evidence that cash transfer programmes have a positive influence on nutrition, school enrolment and utilisation of health services (DFID 2005b). There may, therefore, be a case for arguing that investments will have longterm economic benefits but such investments in the future productivity of children take time to be realised.

It is important also to consider the short-term macroeconomic implications of increased expenditure, especially if it is aid-financed. The fear of Dutch disease overshadows this field. This refers to the theory that inflows of foreign aid will have destabilising macroeconomic impacts. Foreign aid is received by governments which exchange it for local currency with the central bank. If this money is then spent, it increases domestic demand, typically the demand for non-tradables. This increase in demand is then suggested to increase prices and wages in the non-tradable sector, leading to increased inflation. It is further hypothesised that this increase in the prices of non-tradables shifts the allocation of productive assets into the sector and away from the production of tradables. If there are 'learning by doing' factors at work in the tradables sector this will reduce the competitiveness of the sector, harming exports. The central bank then sells the foreign currency, which increases its availability relative to the domestic currency, leading to an appreciation of the local currency, further harming exports. 
There is evidence that the Dutch disease scenario can happen but there is also evidence that it need not always be so. The argument that Dutch disease will occur assumes that the economy of the recipient country is operating at full employment on its production possibility frontier (McKinley 2005). In reality, many developing countries' economies suffer from an under-utilisation of productive resources characterised by high levels of involuntary unemployment and under-employment resulting from deficient aggregate demand. The supply side may well be able to respond to the increased demand thereby reducing the inflationary impact (McKinley 2005). In addition, fiscal expansions can be directed toward productivity-enhancing expenditures that offset the negative impacts on competitiveness, although the nature of such expenditures also has distributional implications (Adam and Bevan 2006). Linked to this is the possibility that, particularly in low-income settings, public expenditures can crowd in private investment, again increasing supply and productivity and limiting impact (McKinley 2005). On the monetary side, the increase in the availability of foreign exchange allows for accumulation of reserves or financing of imports. Some central banks retain foreign exchange in reserves, avoiding the appreciation of the exchange rate but effectively negating the transfer of resources (Chowdhury and McKinley 2006). If the increased availability of exchange is directed towards the purchase of productivity-enhancing capital goods, the impact on competitiveness could even be positive.

The evidence that Dutch disease occurs is mixed, particularly in recent years as understandings of how to manage the inflow have improved reducing the occurrence of negative impacts (Chowdhury and McKinley 2006). In general, the short-term negative macroeconomic implications, if they do occur, can be reversed if productivity is enhanced, which requires that aid is spent appropriately (Lewis 2005). Of course a point will eventually be reached where supply-side responses cannot keep up, but that point is not fixed but rather shaped by the type of spending and interventions undertaken.

It is important therefore that increases in aid lead to delivery and that this delivery results in productivity enhancement (such as investments in appropriate new technology) and/or a supply-side response (through for example, the increased use of under-utilised capacity) to increased demand. Cash transfers have the potential to increase productivity and result in increased demand for goods produced in responsive and labour-intensive sectors, supporting employment creation, growth and reducing the impact on inflation.

In addition to the long-run productivity outcomes resulting from investments in children, there is reason to believe, and evidence, that cash transfers have positive labour market outcomes via increased participation and productivity improvements. Starving is a full-time job, making productive employment, employment search or selfemployment difficult. The evidence that cash transfers to households have negative incentive impacts on adult employment within those households is weak, particularly for poor households, unless the amounts involved are substantial, which is rarely the case (Samson et al. 2001). Recent evidence from South Africa, Brazil and Mexico has all suggested the opposite, with increased adult labour force participation in response to family grants (DFID 2005b). Cash transfers may often increase individuals' capacity to search for work, in particular assisting in the pursuit of high risk-high return approaches to job searching as well as assisting individuals to enter the informal sector (Samson et al. 2004).

\section{Cash transfers may well stimulate a supply side} response as a result of increased consumption by the poor (Samson et al. 2001). The expenditure patterns of poor households tend to be directed towards food and other basic goods as well as to services in the informal sector. These sectors have high employment elasticities and, in the context of high unemployment, may be responsive to increases in demand. There may be a lag in some of these sectors but the increased availability of foreign exchange leaves open the possibility for short-term imports, particularly of basic food stuffs, so as to avoid inflationary pressure. Moreover, the high labour elasticities relate not only to the production of basic goods but their delivery, which is likely to be highly responsive to changes in demand.

For domestically financed programmes, this demand pattern and its impact on supply is likely to be more pronounced than for aid-financed programmes. The redistribution associated with cash transfers shifts the composition of aggregate demand. Wealthier households are likely to have consumption patterns that support higher imports and economic sectors with low employment elasticities. The redistribution may well be employment generating and improve 
the current account balance of payments (Samson et al. 2001). That said, although wealthier households tend to borrow more, the net impact on savings is still likely to be negative (Samson et al. 2004), which requires context-specific consideration.

At the macro level, cash transfers have the added benefit of directly reaching the poor. Adam and Bevan (2006) note that generally, the non-poor are the immediate beneficiaries of expanded government expenditure, because as workers, they benefit from the increased demand for goods and services. As a result of directly providing to the poor, cash transfers have the potential to reduce inequality (Soares et al. 2006), rather than increase it, through direct stimulation of the productive sector.

Macroeconomic stability may, however, not be the most important consideration when considering expanded government spending (Lewis 2005). Institutional weakness and lack of skilled personnel are concerns for both domestically and aid-financed responses. Reliance on uncertain aid flows and associated overexposure provide an additional worry for aid-financed programmes, as does the potential for heavy donor involvement and the establishment of vertical programmes with specific targets that fail to strengthen, and may even weaken, systems (Lewis 2005).

Cash transfers are less labour intensive and require less administration than in-kind transfers (Harvey 2005), although the possibility of corruption and institutional strain do need to be given careful consideration. The success of existing programmes suggests that these issues, while very real, can be dealt with. Cash transfers therefore avoid placing as heavy a demand on a country's stock of skilled professionals that would occur if a more serviceorientated response were implemented. Such services increase the demand for social workers and health professions when both categories of professional are typically in short supply - especially in a context of high HIV prevalence. As a result, in the short term, the additional demand can lead to increased wages and loss of staff from other interventions. In this regard, the potential negative implications of increased expenditure are less likely for cash transfers than for labour-intensive responses.

Uncertainty of aid flows and excessive donor involvement raise a more important issue. Responses to children living in difficult circumstances as a result of HIV and AIDS or other causes should be ongoing and stable. Aid provides important short-term support but also distracts attention from the bigger picture and the longer term.

Poverty, HIV and AIDS, compromised child wellbeing and many other social ills are the result of the failure to address local and international inequalities. The wealthy world gives aid while still protecting their advantaged position in international trade and making little effort to relieve the debt burden. In the poor world, wealthy elites continue to live lives of excess surrounded by poverty. In the long term, what is needed is fairer trade, reduced debt, more efficient government, stronger democracies and reduced inequalities. They are all linked; separating problems out and discussing symptomatic responses diverts attention.

Linking the debate about development to aid, whether in general or specifically in response to children affected by HIV and AIDS, casts the wealthy as noble saviours. Considering the challenge within the context of poverty and how it is linked with global power imbalances casts the wealthy, wherever they may live, as bullies. The truth lies somewhere inbetween. Aid, although problematic at times, is an important source of support to developing countries and a meaningful expression of a belief in a shared humanity, but it is a small part of the picture. $A$ spotlight on programmatic responses supported by international aid leaves the bigger picture, of unfair terms of trade, global power imbalances and debilitating debt, in the dark. The global economic system has consequences for families and their ability to care and support children, including those affected by HIV and AIDS. The conceptual distance between the debates needs to be narrowed so that important symptomatic responses supported by aid do not slow, or distract from, long-term solutions.

\section{Conclusions}

Countries do in fact afford today's response to children affected by HIV and AIDS. The problem is that this response is often inadequate and borne by families and communities often from the poorest segments of society.

There are ways in which governments can support these families, but the nature of the support must consider the context of poverty in which many 
children are living. Specific programmes targeted at those affected are needed. More needed, however, are efforts addressing the detrimental impact of poverty on children and strengthening families' ability to help children through this crisis and others.

Cash transfers are not a magic bullet but they do provide a means to support children that has been proven effective in a variety of settings. Cash helps resource families and provides the means to help access other important services. The design of such interventions, whether they carry conditions and what size of grant is appropriate, needs further consideration, but they cannot be discounted out of hand on the grounds of cost. The macroeconomic implications of cash transfers may well be positive. This suggests that something can indeed be done without a sacrifice of future development.

There is a limit to what can be afforded and if cash transfer programmes were to be continually increased in size and coverage, future development would be hindered. The point at which these negative impacts will be felt, and to what extent they are acceptable costs of fulfilling children's rights today, will be subjective and context-specific. The

\section{References}

Adam, C. and Bevan, D. (2006) 'Aid and the Supply Side: Public Investment, Export Performance, and the Dutch Disease in Low-Income Countries', The World Bank Economic Review 20.2: 261-90

Ainsworth, M.; Beegle, K. and Koda, G. (2005) 'The Impact of Adult Mortality and Parental Deaths on Primary Schooling in North-Western Tanzania', Journal of International Development 41: 412-39

Anderson, E. and Hague, S. (2007) The Impact of Investing in Children: Assessing the Cross-Country Econometric Evidence, ODI Working Paper 280, London: Overseas Development Institute (ODI)

Arnab, R. and Serumaga-Zake, A. (2006) 'Orphans and Vulnerable Children in Botswana: the Impact of HIV/AIDS', Vulnerable Children and Youth Studies 1: 221-9

Beegle, K.; De Weerdt, J. and Dercon, S. (2005) Orphanhood and the Long-Run Impact on Children, Washington DC: World Bank

Chowdhury, A. and McKinley, T. (2006) Gearing Macroeconomic Policies to Manage Large Inflows of ODA: The Implications for HIV/AIDS Programmes, question of affordability then links to the question of what constitutes adequate care. If adequate care can be achieved before the negative consequences of increased spending kick in, then countries can afford to respond. If, however, adequate care would require injection of resources well beyond the point at which negative implications start to manifest, then countries cannot afford to fully respond.

Numerous evaluations of cash transfer programmes have shown that the injection of even a very small amount of money into households can have a positive impact on children's wellbeing (DFID 2005b). These results combined with the above discussion suggest that responses which could move outcomes in the right direction are affordable. Moving in the right direction is, however, different from mounting an adequate response. This is not to suggest that the needs of poor children can be fully met with modest resources. If the measure of adequate care was the level of spending on wealthy children, then the answer to the question posed in this article is that countries cannot afford to respond That said, they can certainly afford to do much more than many are doing now and with support from others, more still, and in a fairer world still more.
IPC Working Paper 17, Brasilia: United Nations Development Programme (UNDP)

Cluver, L. and Gardner, F. (2006) 'Psychological Wellbeing of Children Orphaned by AIDS in Cape Town, South Africa', Annals of General Psychiatry 5: 8

DFID (2005a) Can Low-income Countries in Africa Afford Social Transfers? Social Protection Briefing Note Series 2, London: Department for International Development (DFID)

DFID (2005b) Social Transfers and Chronic Poverty: Emerging Evidence and the Challenge Ahead, DFID Practice Paper, London: Department for International Development (DFID)

Foster, G. (2005) Bottlenecks and Drip-feeds Channelling Resources to Communities Responding to Orphans and Vulnerable Children in Southern Africa, London: Save the Children

Gregson, S.; Nyamukapa, C.; Garnett, G.; Wambe, M. and Lewis, J. (2005) 'HIV Infection and Reproductive Health in Teenage Women Orphaned and Made Vulnerable by AIDS in Zimbabue', AIDS Care 17: 785-94 
Harvey, P. (2005) Cash and Vouchers in Emergencies, HPG Discussion Paper, London: Overseas Development Institute (ODI)

Lewis, M. (2005) Addressing the Challenge of HIV/AIDS: Macroeconomic, Fiscal and Institutional Issues, CGD Working Paper 58, Washington DC: Center for Global Development

McKinley, T. (2005) Why is 'the Dutch Disease' Always a Disease? The Macroeconomic Consequences of Scaling Up ODA, IPC Working Paper 10, Brasilia: United Nations Development Programme (UNDP)

Monasch, R. and Boerma, J. (2004) 'Orphanhood and Childcare Patterns in Sub-Saharan Africa: an Analysis of National Surveys from 40 Countries', AIDS 18: S55-S65

Pal, K.; Behrendt, C.; Leger, F; Cichon, M. and Hagemejer, K. (2005) Can Low Income Countries Afford Basic Social Protection? First Results of a Modelling Exercise. Issues in Social Protection, ILO Discussion Paper 13, Geneva: International Labour Organization (ILO)

Richter, L. and Foster, G. (2006) The Role of the Health Sector in Strengthening Systems to Support Children's Healthy Development in Communities Affected by HIV/AIDS: A Review, Geneva: World Health Organization (WHO)
Samson, M.; Lee, U.; Ndlebe, A.; MacQuene, K.; van Niekerk, I.; Gandhi, V. and Harigaya, T. (2004) The Social and Economic Impact of South Africa's Social Security System, EPRI Research Paper 37, Cape Town: Economic Research Institute

Samson, M.; Babson, O.; Haarmann, C.; Haarmann, D.; Khathi, G.; MacQuene, K. and Van Neikerk, I. (2001) The Economic Impact of a Basic Income Grant in South Africa, EPRI Research Paper 21, Cape Town: Economic Research Institute

Soares, F.; Soares, S.; Medeiros, M. and Osorio, R. (2006) Cash Transfer Programmes in Brazil: Impacts on Inequality and Poverty, IPC Working Paper 21, Brasilia: United Nations Development Programme (UNDP)

Stover, J.; Bollinger, L.; Walker, N. and Monasch, R. (2006) 'Resource Needs to Support Orphans and Vulnerable Children in sub-Saharan Africa', Health Policy and Planning 22: 21-7

UNAIDS (Joint United Nations Programme on HIV/AIDS) (2005) Resource Needs for an Expanded Response to AIDS in Low- and Middle-Income Countries, Geneva: UNAIDS

UNAIDS (1999) A Review of Household and Community Responses to the HIV/AIDS Epidemic in the Rural Areas of sub-Saharan Africa, Geneva: UNAIDS 